\title{
Venous thromboembolism in patients receiving multimodality therapy for thoracic malignancies
}

\author{
Apurva Patel, MD, Masaki Anraku, MD, Gail E. Darling, MD, Frances A. Shepherd, MD, \\ Andrew F. Pierre, MD, Thomas K. Waddell, MD, Shaf Keshavjee, MD, and Marc de Perrot, MD, MSc
}

Objective: The rate of venous thromboembolism in patients undergoing multimodality therapy for lung malignancy and the impact of preoperative venous thromboembolism on postoperative outcome have not been analyzed systematically.

Methods: We performed a retrospective review of all patients undergoing induction therapy before lung resection for non-small cell lung cancer and malignant pleural mesothelioma at the University Health Network between January 1996 and December 2007.

Results: Venous thromboembolism developed in $23(12.3 \%)$ of 186 patients undergoing induction therapy. The venous thromboembolism was diagnosed during induction therapy in 11 patients. The proportion of pulmonary embolism was higher during induction therapy (9/11 patients), whereas deep venous thromboses were observed predominantly postoperatively $(7 / 12$ patients $)(P=.02)$. The risk of postoperative complications or death was not increased in patients undergoing surgery despite a preoperative diagnosis of venous thromboembolism. However, the risk of postoperative pulmonary embolism was higher in patients undergoing surgery without insertion of an inferior vena cava filter $(1 / 2$ patients vs $0 / 7$ after insertion of an inferior vena cava filter, $P=.047)$. The overall survival was similar between patients with or without venous thromboembolism complications.

Conclusion: This study demonstrates that venous thromboembolism events in patients undergoing multimodality therapy for lung malignancies is high and deserves careful consideration. Patients with a venous thromboembolism diagnosis during induction therapy may potentially benefit from a temporary inferior vena cava filter before surgery to limit the risk of recurrent pulmonary embolism. A preoperative diagnosis of venous thromboembolism, however, does not affect early and late outcomes after surgery and should not be viewed as a negative prognostic marker.

Venous thromboembolism (VTE) is a common complication that has been studied extensively in postsurgical patients because of its impact on morbidity and mortality. ${ }^{1}$ The rate of postoperative VTE has decreased dramatically since a large multicenter trial demonstrated that low-dose heparin (5000 units) administered 2 hours before incision and then every 8 hours postoperatively significantly reduced the incidence of VTE. ${ }^{2}$ However, the impact of induction therapy on the incidence of preoperative and postoperative VTE in patients undergoing lung resection for malignancy has not been reported. This question is of importance considering that an increasing number of patients with lung cancer are treated with induction chemotherapy or chemoradiation therapy for locally advanced disease. ${ }^{3,4}$ Preoperative VTE may increase the risk of surgery because of a reduction in

\footnotetext{
From the Toronto General Hospital and Princess Margaret Hospital, University Health Network, Toronto, Ontario, Canada.

Received for publication Oct 9, 2008; revisions received Jan 10, 2009; accepted for publication Feb 9, 2009; available ahead of print April 13, 2009.

Address for reprints: Marc de Perrot, MD, MSc, Division of Thoracic Surgery, Toronto General Hospital, 9N-961, 200 Elizabeth Street, Toronto, Ontario M5G 2C4, Canada (E-mail: marc.deperrot@uhn.on.ca).

J Thorac Cardiovasc Surg 2009;138:843-8

$0022-5223 / \$ 36.00$

Copyright (c) 2009 by The American Association for Thoracic Surgery

doi:10.1016/j.jtcvs.2009.02.028
}

the pulmonary vascular bed in patients with other potential comorbidities and be associated with a higher risk of postoperative thrombotic and bleeding events.

The aim of this study is to review the rate of preoperative and postoperative VTE in patients treated with induction therapy and to analyze the impact of preoperative VTE on postoperative outcome. On the basis of our experience and that of the literature, recommendations for management of patients presenting with preoperative VTE are presented.

\section{MATERIALS AND METHODS}

We performed a retrospective chart review of 186 consecutive patients undergoing induction therapy for non-small cell lung cancer (NSCLC) and malignant pleural mesothelioma (MPM) at the University Health Network between January 1996 and December 2007. The study was approved by the Research Ethics Board of the University Health Network.

All patients with NSCLC presenting with superior sulcus tumors, spinal involvement, or stage IIIA (N2) disease underwent induction chemoradiation therapy with cisplatin-etoposide concurrently with 45 Gy of radiation, and all patients with MPM underwent induction chemotherapy with cisplatin-vinorelbine $(n=26)$, cisplatin-pemetrexed $(n=24)$, cisplatin-raltitrexed $(n=6)$, cisplatin-gemcitabine $(n=4)$, or cisplatin-doxorubicin $(\mathrm{n}=3)$ followed by extrapleural pneumonectomy (Table 1$)$. Surgery was usually performed 3 to 6 weeks after completion of induction therapy.

Prophylaxis for VTE during the study period was unfractionated subcutaneous heparin 5000 units twice daily starting the day of surgery until hospital discharge. Pneumatic stockings have been used systematically during 


$$
\begin{aligned}
& \text { Abbreviations and Acronyms } \\
& \begin{aligned}
\text { IVC } & =\text { inferior vena cava } \\
\text { MPM } & =\text { malignant pleural mesothelioma } \\
\text { NSCLC } & =\text { non-small cell lung cancer } \\
\text { PE } & =\text { pulmonary embolism } \\
\text { VTE } & =\text { venous thromboembolism }
\end{aligned}
\end{aligned}
$$

the perioperative period since 2003. No VTE prophylaxis was used during induction therapy. No systematic screening for VTE was performed before or after surgery. The decision to investigate for deep vein thrombosis or pulmonary embolism (PE) was decided on the basis of clinical suspicion.

PE had to be documented by computed tomography scan or V/Q scan, and deep vein thrombosis had to be documented by Doppler ultrasonography. Patients presenting with sudden death from a suspected PE were also included in this study. Patients diagnosed with VTE during induction therapy were switched to unfractionated intravenous heparin at the time of surgery, and therapeutic dose of heparin was resumed within 24 to 96 hours postoperatively. The decision to insert an inferior vena cava (IVC) filter or not was made by the surgical team on a case-by-case basis. Data were collected from electronic patient records and paper charts. Age, gender, type of malignancy, type of surgery, timing of VTE, management of VTE, and postoperative complications were recorded for each patient.

Postoperative deaths included all patients who died within 30 days of surgery or during the same hospitalization. Postoperative complications were defined as complications within 30 days of surgery or during the same hospital stay. Major cardiac and pulmonary complications were defined as grade 3, 4, or 5 complications according to the National Cancer Institute Common Terminology Criteria for Adverse Events 3.0 guidelines.

Results are presented in absolute number and percentage, or median and range. Categoric variables were compared by chi-square analysis, and numeric variables were compared by Student $t$ test. Cumulative proportion of VTE from the start of induction therapy was obtained by using the Kaplan-Meier method. Multivariate analysis was assessed by logistic regression analysis to determine independent predictors of major cardiopul- monary complications and postoperative death. Overall survival was estimated using the Kaplan-Meier method. Differences in survival were tested for significance by the log-rank test. Because the characteristics of patients with VTE complications were different (Table 1), a propensity score was developed to reduce selection bias in comparing outcomes. ${ }^{5,6}$ The propensity score for each patient who underwent surgery was calculated on the basis of gender, age (continuous variable), type of cancer (NSCLC vs MPM), and induction treatment (chemotherapy alone vs chemoradiotherapy). Cox regression modeling was then performed with the calculated propensity scores and the event of VTE (either pre- or postoperative vs non-VTE) as variables to determine if VTE was an independent predictor of outcome. Statview V (Abacus Concept, Berkeley, CA) and STATA 10 (StataCorp LP, College Station, TX) were used for all analyses.

\section{RESULTS}

VTE developed in $23(12.3 \%)$ of 186 patients undergoing induction therapy during the 11-year study period. The cumulative proportion of VTE from the start of induction therapy is presented in Figure 1. VTE was diagnosed during induction therapy in 11 patients and postoperatively in 12 patients. The proportion of $\mathrm{PE}$ was higher during induction therapy (9/11 patients), whereas deep vein thromboses were observed predominantly postoperatively (7/12 patients) $(P=.02)$. Among patients with NSCLC, VTE was seen in 8 of 57 patients $(14 \%)$ with adenocarcinoma compared with 11 of 66 patients $(17 \%)$ with other histologic subtypes of NSCLC $(P=.7)$.

Among the 12 patients with VTE postoperatively, 8 were diagnosed while in hospital (after admission to the intensive care unit in 4 patients) and 4 were diagnosed after being dis-

\begin{tabular}{|c|c|c|c|c|}
\hline & $\begin{array}{l}\text { All patients } \\
(\mathbf{n}=\mathbf{1 8 6})\end{array}$ & $\begin{array}{l}\text { Patients with VTE complications } \\
\qquad(\mathrm{n}=\mathbf{2 3})\end{array}$ & $\begin{array}{l}\text { Patients without VTE complications } \\
\qquad(\mathrm{n}=163)\end{array}$ & $P$ value \\
\hline Age, y & & & & .6 \\
\hline Median & 60 & 63 & 60 & \\
\hline Range & $21-80$ & $21-75$ & $32-80$ & \\
\hline Gender & & & & .9 \\
\hline Male & 122 & 15 & 107 & \\
\hline Female & 64 & 8 & 56 & \\
\hline Indications for induction therapy & & & & .07 \\
\hline MPM & 63 & 4 & 59 & \\
\hline NSCLC & 123 & 19 & 104 & \\
\hline Induction therapy & & & & .2 \\
\hline Chemoradiation therapy & 119 & 17 & 102 & \\
\hline Chemotherapy alone & 67 & 6 & 61 & \\
\hline Type of surgery & & & & .4 \\
\hline Extrapleural pneumonectomy & 48 & 3 & 45 & \\
\hline Pneumonectomy & 20 & 4 & 16 & \\
\hline Lobectomy & 90 & 13 & 77 & \\
\hline Wedge resection & 2 & 1 & 1 & \\
\hline No surgery & 26 & 2 & 24 & \\
\hline
\end{tabular}
charged from hospital. Postoperative VTE did not develop in any patient during consolidation chemotherapy. The introduction of pneumatic stockings in 2003 did not reduce the risk of postoperative VTE (4 postoperative VTEs in 77

TABLE 1. Patient characteristics

VTE, Venous thromboembolism; $M P M$, malignant pleural mesothelioma; $N S C L C$, non-small cell lung cancer. 


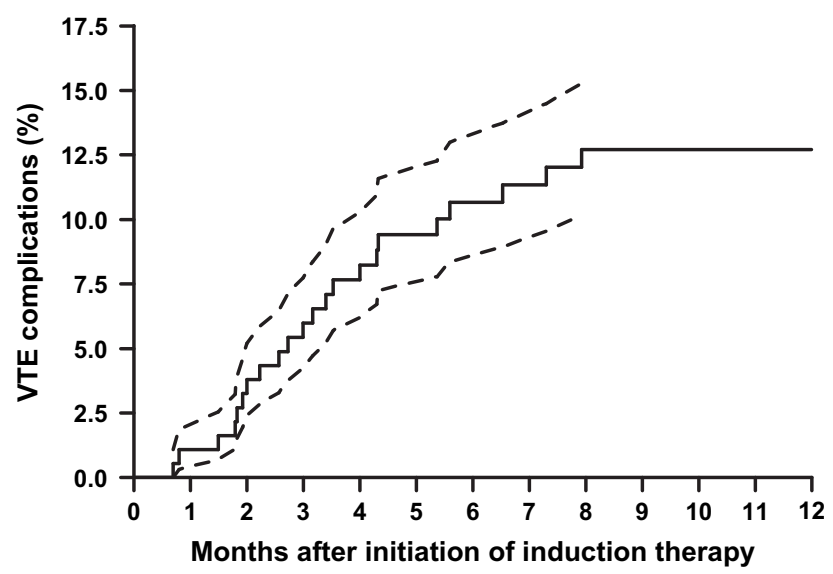

FIGURE 1. Cumulative proportion of VTE complications after initiation of induction therapy. Dashed lines represent the $95 \%$ confidence interval. $V T E$, Venous thromboembolism.

patients undergoing surgery between 1996 and 2002 and 5 postoperative VTEs in 83 patients between 2003 and 2007 $(5.2 \%$ vs $6.0 \%, P=.8)$.

Among the 11 patients diagnosed with VTE during induction therapy, 9 proceeded to surgery: Five patients underwent a lobectomy, 2 patients underwent a pneumonectomy, and 2 patients underwent an extrapleural pneumonectomy. The period of time between the diagnosis of VTE and surgery ranged from 17 to 107 days (median 28 days). In 2 patients, the treatment plan was changed after the diagnosis of VTE. In 1 patient with large bilateral PE, the radiation
TABLE 2. Major postoperative cardiopulmonary complications*

\begin{tabular}{lc}
\hline \multicolumn{1}{c}{ Complications } & No. of patients $(\%)$ \\
\hline Major cardiopulmonary complications & $42(26 \%)$ \\
Pulmonary complications & \\
Respiratory failure/Pneumonia & 21 \\
Empyema & 6 \\
Bronchopleural fistula & 3 \\
Pulmonary emboli & 3 \\
Cardiac complications & \\
Atrial fibrillation & 19 \\
Myocardial infarction & 1 \\
Cardiac herniation & 1 \\
\hline
\end{tabular}

*Some patients had $>1$ complication.

dose was boosted from 45 to $60 \mathrm{~Gy}$ in the event that surgery was not going to be feasible. In the second patient, a left pneumonectomy was planned and surgery was delayed by 8 weeks to allow resolution of a large right-sided PE. In the remaining 7 patients, the protocol of induction therapy and surgery was completed as anticipated with no delay in surgery despite the VTE. Seven patients underwent insertion of an IVC filter immediately before surgery.

Among 160 patients undergoing surgery, major cardiopulmonary complications developed in $42(26 \%)$ and 10 $(6.3 \%)$ died postoperatively (Table 2$)$. The risk of major cardiopulmonary complications was significantly higher in men and in patients aged more than 60 years (Table 3). Patients undergoing pneumonectomy were also at greater risk of major cardiopulmonary complications and death than patients

TABLE 3. Risk factors for major cardiopulmonary complications

\begin{tabular}{|c|c|c|c|c|c|}
\hline \multirow[b]{2}{*}{ Factors } & \multirow{2}{*}{$\begin{array}{c}\text { All patients } \\
\text { undergoing surgery }(n=160)\end{array}$} & \multicolumn{2}{|c|}{ Complications } & \multicolumn{2}{|c|}{$P$ value } \\
\hline & & Yes $(n=42)$ & No $(n=118)$ & Univariate analysis & Multivariate analysis \\
\hline Type of resection & & & & .06 & .06 \\
\hline Pneumonectomy or EPP & 68 & 23 & 45 & & \\
\hline Lobectomy or wedge & 92 & 19 & 73 & & \\
\hline Side of surgery & & & & .6 & 6 \\
\hline Right & 89 & 22 & 67 & & \\
\hline Left & 71 & 20 & 51 & & \\
\hline VTE during induction therapy & & & & .2 & .2 \\
\hline Yes & 9 & 4 & 5 & & \\
\hline No & 151 & 38 & 113 & & \\
\hline Age $>60 y$ & & & & .04 & .04 \\
\hline Yes & 74 & 25 & 49 & & \\
\hline No & 86 & 17 & 69 & & \\
\hline Gender & & & & .04 & .04 \\
\hline Male & 101 & 32 & 69 & & \\
\hline Female & 59 & 10 & 49 & & \\
\hline Indication for induction therapy & & & & .6 & .3 \\
\hline MPM & 48 & 14 & 34 & & \\
\hline NSCLC & 112 & 28 & 84 & & \\
\hline Type of induction therapy & & & & .3 & 6 \\
\hline Chemoradiation therapy & 108 & 27 & 81 & & \\
\hline Chemotherapy & 52 & 15 & 37 & & \\
\hline
\end{tabular}

$E P P$, Extrapleural pneumonectomy; $V T E$, venous thromboembolism; $M P M$, malignant pleural mesothelioma; $N S C L C$, non-small cell lung cancer. 
TABLE 4. Risk factors for postoperative deaths

\begin{tabular}{|c|c|c|c|c|c|}
\hline \multirow[b]{2}{*}{ Factors } & \multirow[b]{2}{*}{$\begin{array}{c}\text { All patients } \\
\text { undergoing surgery }(n=160)\end{array}$} & \multicolumn{2}{|c|}{ Postoperative death } & \multicolumn{2}{|c|}{$P$ value } \\
\hline & & Yes $(\mathbf{n}=10)$ & No $(\mathbf{n}=150)$ & Univariate analysis & Multivariate analysis \\
\hline Type of resection & & & & .01 & .03 \\
\hline Pneumonectomy or EPP & 68 & 8 & 60 & & \\
\hline Lobectomy or wedge & 92 & 2 & 90 & & \\
\hline Side of surgery & & & & .3 & .4 \\
\hline Right & 89 & 7 & 82 & & \\
\hline Left & 71 & 3 & 68 & & \\
\hline VTE during induction therapy & & & & .4 & .9 \\
\hline Yes & 9 & 0 & 9 & & \\
\hline No & 151 & 10 & 141 & & \\
\hline Age $>60 y$ & & & & .8 & .8 \\
\hline Yes & 74 & 5 & 69 & & \\
\hline No & 86 & 5 & 81 & & \\
\hline Gender & & & & 6 & 6 \\
\hline Male & 101 & 7 & 94 & & \\
\hline Female & 59 & 3 & 56 & & \\
\hline Indication for induction therapy & & & & .5 & .8 \\
\hline MPM & 48 & 4 & 44 & & \\
\hline NSCLC & 112 & 6 & 106 & & \\
\hline Type of induction therapy & & & & .2 & .2 \\
\hline Chemoradiation therapy & 108 & 5 & 103 & & \\
\hline Chemotherapy & 52 & 5 & 47 & & \\
\hline
\end{tabular}

EPP, Extrapleural pneumonectomy; $V T E$, venous thromboembolism; $M P M$, malignant pleural mesothelioma; $N S C L C$, non-small cell lung cancer.

undergoing lobectomy (Tables 3 and 4). A preoperative diagnosis of VTE, however, did not increase the risk of postoperative cardiopulmonary complications or death (Tables 3 and 4). Major positive complications developed in 3 of the 9 patients $(33 \%)$ with a preoperative diagnosis of VTE: recurrent $\mathrm{PE}(\mathrm{n}=1)$, hemothorax $(\mathrm{n}=1)$, and pneumonia $(\mathrm{n}=1)$. Among patients with a diagnosis of VTE made during induction therapy, the risk of postoperative PE was higher in those undergoing surgery without insertion of an IVC filter (PE developed in $1 / 2$ patients without IVC filter vs $0 / 7$ patients with an IVC filter, $P=.047$ ).

After a median follow-up of 1.5 years after surgery, 11 of 21 patients $(52 \%)$ with a history of VTE and 80 of 139 patients $(58 \%)$ without VTE have died $(P=.7)$. The overall survival was similar between patients with or without VTE complications (Figure 2). After adjustment for the propensity score, the hazard ratio of VTE was 1.004 (95\% confidence interval, $0.53-1.89 ; P=.99$ ), confirming that preoperative or postoperative VTE did not affect patients' survival after surgery. Among patients with a preoperative diagnosis of VTE, 5 are alive without recurrence 2.5 to 8.5 years after surgery (median 2.1 years), and the 5-year survival reached $54 \%$ in patients with NSCLC (Figure 3).

\section{DISCUSSION}

This study demonstrates that the rate of VTE in patients undergoing induction therapy for lung malignancy is high, ranging between $6.3 \%$ in patients undergoing induction chemotherapy for MPM and $15.4 \%$ in patients undergoing induction chemoradiation therapy for NSCLC. The number of VTE events was higher than in other series of lung resection for malignancy and relates to the fact that approximately half of the VTE complications occurred during induction therapy before surgery. ${ }^{7-9}$

The rate of postoperative VTE in our series ranged between $7 \%$ and $8 \%$. The majority of postoperative VTE occurred in patients admitted to the intensive care unit for major postoperative complications or in patients already

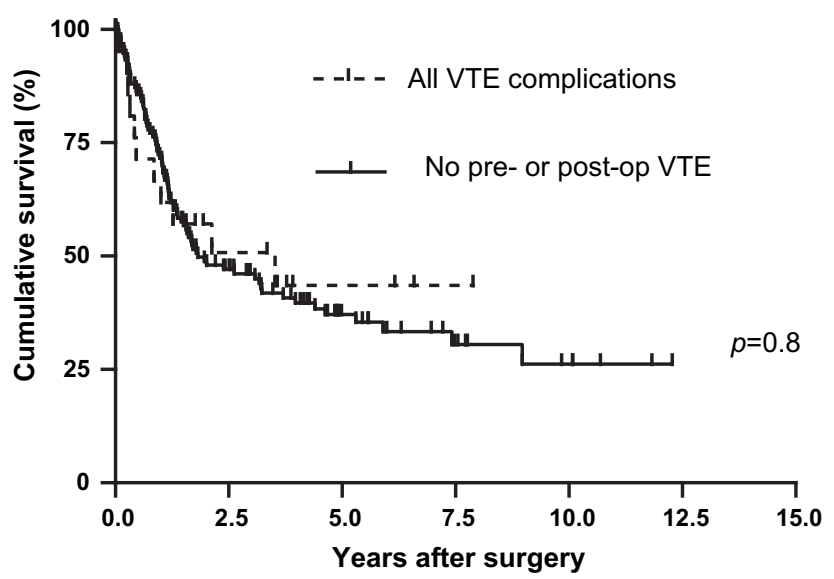

FIGURE 2. Overall survival of patients with or without VTE complications. VTE, Venous thromboembolism. 


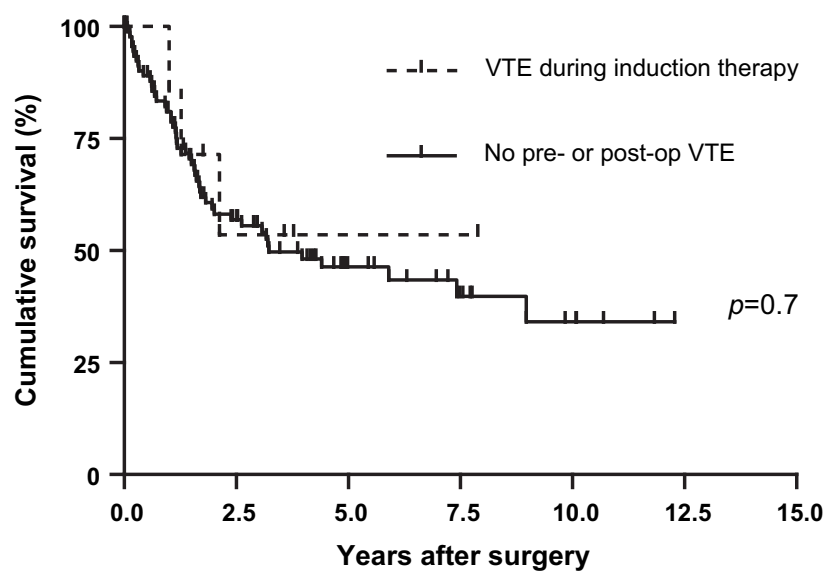

FIGURE 3. Survival of patients with NSCLC with a VTE diagnosis during induction therapy compared with patients with NSCLC without preoperative or postoperative VTE complications. VTE, Venous thromboembolism.

discharged from the hospital. This experience is similar to that reported by other groups and suggests that particular attention should be given to these 2 groups of patients. ${ }^{7}$

During the past decade, early hospital discharge has been associated with an increasing incidence of VTE in the outpatient setting, and some studies suggest that continued prophylaxis after hospital discharge may be beneficial in patients at high risk of VTE. ${ }^{10,11}$ In our experience, VTE developed in 4 patients after being discharged from the hospital and 2 of them died suddenly at home from a presumed PE. Thus, patients undergoing induction therapy seem to be a high-risk group and should potentially be kept on prophylactic anticoagulation after hospital discharge for up to 4 weeks after surgery. The guidelines recently published by the American College of Chest Physicians and American Society of Clinical Oncology also suggest that some selected patients at high risk of VTE may benefit from continuing thromboprophylaxis after hospital discharge with low molecular weight heparin for up to 28 postoperative days. ${ }^{12,13}$

VTE developed in 11 of 186 patients during induction therapy. This translates into an incidence of VTE of approximately 59 per 1000 patient-years in our experience. This incidence is similar to other studies looking specifically at the association between VTE and lung cancer with an incidence ranging between 44 and 100 per 1000 person-years. ${ }^{14,15} \mathrm{~A}$ diagnosis of VTE during induction therapy did not increase the risk of not proceeding to surgery. It did, however, lead to a change in the treatment plan in 2 of the 9 patients scheduled for surgery. The radiation dose was boosted from 45 to $60 \mathrm{~Gy}$ in 1 patient, and surgery was delayed to allow resolution of the PE in 1 patient.

Although a preoperative diagnosis of VTE did not have a significant impact on the overall risk of postoperative complications or deaths, complications developed in 2 patients that were directly related to their VTE postoperatively. Recurrent PE developed in 1 patient on the second postopera- tive day, and a tension hemothorax in the pneumonectomy cavity developed in 1 patient. The only patient in whom recurrent PE developed did not have an IVC filter inserted before surgery. The role of an IVC filter in a patient with acute PE remains controversial, and firm recommendations cannot be drawn from this small series of patients. However, we think that the specific subgroup of patients presenting with clinically significant VTE during their induction therapy may potentially benefit from a temporary IVC filter because the anticoagulation has to be stopped perioperatively. Temporary IVC filters can be removed after the patient has recovered from the surgery and completed all postoperative therapy, thereby avoiding long-term complications associated with their use. ${ }^{16}$

The resolution of acute PE is maximal during the first 6 weeks after the initiation of therapeutic anticoagulation. ${ }^{17,18}$ Thereafter, improvement may still be observed but at a lower rate. Thus, a period of 6 weeks between the diagnosis of $\mathrm{PE}$ and surgery may be optimal, particularly for patients presenting with large $P E$. The diagnostic workup before surgery should include a V/Q scan and an echocardiogram to ensure that there is complete resolution of the PE and no residual pulmonary hypertension. ${ }^{19}$ The V/Q scan remains a better test than multislice computed tomographic angiogram to rule out chronic thromboembolic disease and will also identify differential perfusion between the right and left lung that may be useful for planning surgery, particularly if a pneumonectomy is anticipated. ${ }^{20}$

Some series suggest that patients with malignancy who develop VTE have a substantially worse survival than patients without VTE. ${ }^{7,21}$ However, it remains unclear whether VTE in surgical patients is a direct cause of poor outcome or a marker of more aggressive malignancy. In our experience, the overall outcome was not significantly different whether patients were diagnosed with VTE or not. By looking more specifically at the group of patients with NSCLC, survival was identical between patients with a VTE diagnosis before surgery and patients without VTE complications before or after surgery. This is similar to the results recently reported from the National Cancer Institute of Canada Clinical Trial Group pooled analysis. ${ }^{22}$ VTE developed in $3 \%$ of the patients treated with adjuvant chemotherapy for stage IB and II NSCLC in the JBR.10 trial, but VTE was not associated with poorer survival in this group of patients with early-stage NSCLC. ${ }^{22,23}$ Thus, we believe that a preoperative diagnosis of VTE should not necessarily be viewed as a negative prognostic marker in early-stage disease and that a diagnosis of VTE should not be a reason to select a nonsurgical approach to potentially curative surgery.

This study has several limitations related to the retrospective nature of the data collection and the mixed patient population. The true prevalence of patients with VTE is likely underestimated because we did not prospectively perform imaging studies to detect patients with asymptomatic VTE. 
The type of induction therapy is also variable between institutions, and, although unlikely, induction therapy with platinum and taxane may have a different impact on the risk of VTE than we observed in our series.

\section{CONCLUSIONS}

This large study of patients undergoing induction therapy for lung malignancy demonstrates that the rate of VTE during induction therapy is high and deserves careful consideration. Patients with a VTE diagnosis during induction therapy may require a change in their treatment plan and are at risk of recurrent VTE and bleeding postoperatively. The insertion of a temporary ICV filter at the time of surgery in patients with a preoperative diagnosis of VTE remains controversial but may be beneficial in this subgroup of patients. The immediate postoperative outcome and longterm survival of patients with a preoperative diagnosis of VTE are similar to those of other patients without any VTE complications. Thus, we believe that a preoperative diagnosis of VTE should not be viewed as a negative prognostic marker and should not be a reason to select a nonsurgical approach to potentially curative surgery.

We thank Dr Luis Garrido-Olivares for assistance with the statistical analysis.

\section{References}

1. Zurawska U, Parasuraman S, Goldhaber SZ. Prevention of pulmonary embolism in general surgery patients. Circulation. 2007;115:302-7.

2. Kakkar VV, Corrigan TP, Fossard DP. Prevention of fatal postoperative pulmonary embolism by low doses of heparin. Lancet. 1975;2:45-51.

3. Fischer S, Darling G, Pierre AF, Sun A, Leighl N, Waddell TK, et al. Induction chemoradiation therapy followed by surgical resection for non-small cell lung cancer (NSCLC) invading the thoracic inlet. Eur J Cardiothorac Surg. 2008; 33:1129-34.

4. Uy KL, Darling G, Xu W, Yi QL, De Perrot M, Pierre AF, et al. Improved results of induction chemoradiation before surgical intervention for selected patients with stage IIIA-N2 non-small cell lung cancer. J Thorac Cardiovasc Surg. 2007;134: 188-93.

5. Blackstone EH. Comparing apples and oranges. J Thorac Cardiovasc Surg. 2002; 123:8-15.

6. Rubin DB. The design versus the analysis of observational studies for causal effects: parallels with the design of randomized trials. Statist Med. 2007;26:20-36.

7. Mason DP, Quader MA, Blackstone EH, Rajeswaran J, DeCamp MM, Murthy SC, et al. Thromboembolism after pneumonectomy for malignancy: an independent marker of poor outcome. J Thorac Cardiovasc Surg. 2006;131:711-8.
8. Sugarbaker DJ, Jaklitsch MT, Bueno R, Richards W, Lukanich J, Mentzer SJ, et al. Prevention, early detection, and management of complications after 328 consecutive extrapleural pneumonectomies. J Thorac Cardiovasc Surg. 2004;128: 138-46.

9. Dentali F, Malato A, Ageno W, Imperatori A, Cajozzo M, Rotolo N, et al. Incidence of venous thromboembolism in patients undergoing thoracotomy for lung cancer. $J$ Thorac Cardiovasc Surg. 2008;135:705-6.

10. Bergqvist D, Agnelli G, Cohen AT, Eldor A, Nilsson PE, Le Moigne-Amrani A, et al. Duration of prophylaxis against venous thromboembolism with enoxaparin after surgery for cancer. $N$ Engl J Med. 2002;346:975-80.

11. Kakkar AK, Brenner B, Dahl OE, Eriksson BI, Mouret P, Muntz J, et al. Extended duration rivaroxaban versus short-term enoxaparin for the prevention of venous thromboembolism after total hip arthroplasty: a double-blind, randomised controlled trial. Lancet. 2008;372:31-9.

12. Geerts WH, Bergqvist D, Pineo GF, Heit JA, Samama CM, Lassen MR, et al. Prevention of venous thromboembolism: American College of Chest Physicians Evidence-Based Clinical Practice Guidelines (8th Edition). Chest. 2008;133(6 Suppl):381S-453S.

13. Lyman GH, Khorana AA, Falanga A, Clarke-Pearson D, Flowers C, Jahanzeb M, et al. American Society of Clinical Oncology guideline: recommendations for venous thromboembolism prophylaxis and treatment in patients with cancer. $J$ Clin Oncol. 2007;25:5490-505.

14. Blom JW, Vanderschoot JP, Oostindiër MJ, Osanto S, van der Meer FJ, Rosendaal FR. Incidence of venous thrombosis in a large cohort of 66,329 cancer patients: results of a record linkage study. J Thromb Haemost. 2006;4: 529-35.

15. Chew HK, Davies AM, Wun T, Harvey D, Zhou H, White RH. The incidence of venous thromboembolism among patients with primary lung cancer. $J$ Thromb Haemost. 2008;6:601-8.

16. Berczi V, Bottomley JR, Thomas SM, Taneja S, Gaines PA, Cleveland TJ. Longterm retrievability of IVC filters: should we abandon permanent devices? Cardiovasc Intervent Radiol. 2007;30:820-7.

17. Ribeiro A, Lindmarker P, Johnsson H, Juhlin-Dannfelt A, Jorfeldt L. Pulmonary embolism: one-year follow-up with echocardiography Doppler and five-year survival analysis. Circulation. 1999;99:1325-30.

18. Ribeiro A, Lindmarker P, Johnsson H, Juhlin-Dannfelt A, Jorfeldt L. Pulmonary embolism: a follow-up study of the relation between the degree of right ventricle overload and the extent of perfusion defects. J Intern Med. 1999;245: 601-10.

19. de Perrot M, Fadel E, McRae K, Tan K, Slinger P, Paul N, et al. Evaluation of persistent pulmonary hypertension after acute pulmonary embolism. Chest. 2007; 132:780-5.

20. Tunariu N, Gibbs SJ, Win Z, Gin-Sing W, Graham A, Gishen P, et al. Ventilationperfusion scintigraphy is more sensitive than multidetector CTPA in detecting chronic thromboembolic pulmonary disease as a treatable cause of pulmonary hypertension. J Nucl Med. 2007;48:680-4.

21. Sorensen HT, Mellemkjaer L, Olsen JH, Baron JA. Prognosis of cancers associated with venous thromboembolism. N Engl J Med. 2000;343:1846-50.

22. Shepherd F, Hasan B, Hicks L, Cheung M, Leighl N, Winton T, et al. Venous thromboembolism (VTE) and non-small cell lung cancer: a pooled analysis of National Cancer Institute of Canada Clinical Trials Group (NCIC CTG) trials. Eur J Cancer. 2007;4(Suppl):361, (Abst 6516).

23. Winton T, Livingston R, Johnson D, Rigas J, Johnston M, Butts C, et al. Vinorelbine plus cisplatin vs. observation in resected non-small-cell lung cancer. $N$ Engl J Med. 2005;352:2589-97. 